\title{
Cost-effectiveness of alternative strategies for integrating MRI into breast cancer screening for women at high risk
}

\author{
C H Ahern ${ }^{1}$, Y-C T Shih ${ }^{2}$, W Dong ${ }^{3}$, G Parmigiani ${ }^{4,5}$ and Y Shen ${ }^{*, 3}$
}

${ }^{1}$ Department of Medicine, Division of Biostatistics, The Dan L. Duncan Cancer Center at Baylor College of Medicine, One Baylor Plaza, BCM600, Houston TX 77030, USA; ${ }^{2}$ Department of Medicine, Section of Hospital Medicine, The University of Chicago, 5841 S Maryland Avenue, MC 5000, Chicago IL 60637, USA; ${ }^{3}$ Department of Biostatistics, The University of Texas M.D. Anderson Cancer Center, 1515 Holcombe Blvd, Unit 1411, Houston TX 77030, USA; ${ }^{4}$ Department of Biostatistics and Computational Biology, Dana-Farber Cancer Institute, 450 Brookline Avenue, Boston MA 02115, USA and ${ }^{5}$ Department of Biostatistics, Harvard School of Public Health, 677 Huntington Avenue, Boston MA 02115, USA

Background: Magnetic resonance imaging (MRI) is recommended for women at high risk for breast cancer. We evaluated the cost-effectiveness of alternative screening strategies involving MRI.

Methods: Using a microsimulation model, we generated life histories under different risk profiles, and assessed the impact of screening on quality-adjusted life-years, and lifetime costs, both discounted at $3 \%$. We compared 12 screening strategies combining annual or biennial MRI with mammography and clinical breast examination (CBE) in intervals of $0.5,1$, or 2 years vs without, and reported incremental cost-effectiveness ratios (ICERs).

Results: Based on an ICER threshold of $\$ 100000 /$ ALY, the most cost-effective strategy for women at $25 \%$ lifetime risk was to stagger MRI and mammography plus CBE every year from age 30 to 74, yielding ICER \$58 400 (compared to biennial MRI alone). At $50 \%$ lifetime risk and with $70 \%$ reduction in MRI cost, the recommended strategy was to stagger MRI and mammography plus $\mathrm{CBE}$ every 6 months $(\mathrm{ICER}=\$ 84400)$. At $75 \%$ lifetime risk, the recommended strategy is biennial MRI combined with mammography plus CBE every 6 months (ICER $=\$ 62800)$.

Conclusions: The high costs of MRI and its lower specificity are limiting factors for annual screening schedule of MRI, except for women at sufficiently high risk.

The average lifetime risk of breast cancer for a woman in the United States is one in eight (Ries et al, 2005). Women who have a strong family history of breast or ovarian cancer, cancerpredisposing $B R C A$ mutations, or other risk factors such as prior thoracic radiation at an early age (e.g., for the treatment of Hodgkin's disease) have an increased risk of developing the disease. For women with an average breast cancer risk, several major cancer societies recommend screening using various combinations of mammography and clinical breast examination (CBE). For women at an increased risk for breast cancer, it has been suggested that further extensions to general screening guidelines such as more frequent examinations, earlier starting ages of screening (e.g., age 30), or additional screening modalities, may be beneficial (Smith et al, 2003). For example, the National Institute for Health and Care Excellence in the United Kingdom suggests that women with high risk for breast cancer should have mammography every year beginning at age 40 , and earlier if they are known to carry certain gene mutations (UK CR, 2012).

One commonly discussed extension is to augment screening mammography with magnetic resonance imaging (MRI). Although MRI has been found to have a higher sensitivity than screening mammography among younger women with dense breasts, reports

*Correspondence: Dr Y Shen; E-mail: yshen@mdanderson.org

Received 13 March 2014; revised 9 July 2014; accepted 21 July 2014; published online 19 August 2014

(c) 2014 Cancer Research UK. All rights reserved 0007-0920/14 
of its specificity have been lower in high-risk women (Kuhl et al, 2003; Kriege et al, 2004; Warner et al, 2004; Leach et al, 2005; Kriege et al, 2006), resulting in a higher rate of false-positive results. In addition, MRI is expensive and its administration and interpretation require more highly trained personnel. Decision makers who are interested in integrating MRI into the screening programme for women at high risk for breast cancer must weigh the potential survival benefit from MRI against its much higher costs and increased false-positive results, which lead to unnecessary testing procedures and a reduction in health utility. Thus it is important to assess the clinical as well as economic implications of adding MRI to current screening programmes for high-risk women so as to identify cost-effective screening strategies involving MRI.

Although there are cost-effectiveness studies of breast MRI screening for women at increased risk for breast cancer, the vast majority of these studies have focused on adding MRI to screening mammography for BRCA1 or BRCA2 carriers (Plevritis et al, 2006; Cott Chubiz et al, 2013; de Bock et al, 2013; Pataky et al, 2013). Findings from these studies have contributed to the development of screening guidelines for women with these mutations. It is now well accepted that annual screening with MRI should be recommended for women with $B R C A 1$ or $B R C A 2$ gene mutations. For other women at high risk for breast cancer, there is currently no consensus on how MRI should be incorporated into clinical practice. Few existing guidelines for MRI in breast cancer screening specifically discuss the level of lifetime risk for breast cancer at which MRI should be recommended. One exception is the MRI screening guideline from the American Cancer Society (ACS; American Cancer Society: Detailed Guide: breast cancer), which recommends an MRI and a mammogram every year for women with a lifetime risk of $20-25 \%$ or greater (Saslow et al, 2007). However, it is unclear how to integrate MRI into the current screening programmes, which typically consist of mammography and CBE. It is also unclear if at this level of lifetime risk the additional benefit from annual MRI screening outweighs the additional costs, or whether a longer screening interval for MRI (e.g. 2 years) is more cost-effective.

Approximately, $10 \%$ of breast cancers are caused by BRCA 1 and $B R C A 2$ mutations (Afonso, 2009); therefore, findings from costeffectiveness studies focusing on women carrying these mutations cannot be generalised to the evaluation of the ACS guideline for MRI screening, as the level of lifetime risk underlying the ACS recommendation targets a much larger group of women at high risk of breast cancer. Other cost-effectiveness studies that did not focus exclusively on BRCA1 or BRCA2 mutation carriers were limited by the types of screening strategies explored in their comparisons, such as the comparison between MRI-only vs mammography-only in Moore et al (2009), or MRI with vs without X-ray mammography in Taneja et al (2009). Neither considered CBE. A recent cost-effectiveness analysis by Saadatmand et al (2013) considered augmenting the current screening practice in the Dutch nationwide screening programme (i.e., biennial mammography from 50 to 75 years) with several screening strategies among women aged 35-50 with familial risk for breast cancer, including the screening strategy of CBE every 6 months combined with annual mammography and MRI explored in a prospective MRI screening study. However, the model in their study was designed to explore what augmentation to the existing screening programme was most cost-effective, instead of investigating how MRI should be incorporated into current practice for high-risk women, with or without mammography plus CBE.

If mammography screening is insufficient for these women and the higher sensitivity of MRI could offer a better alternative, what is the best way to integrate MRI into current clinical practice given its much higher cost and also lower specificity? There are many ways to incorporate MRI into current screening practice of mammography screening combined with CBE. For high-risk women, clinicians may be reluctant to recommend a screening interval of $>1$ year. Given this requirement, several screening strategies involving MRI are possible, such as replacing annual mammography screening plus CBE with annual MRI, alternating mammography plus CBE with MRI every year, performing MRI immediately following annual mammography plus CBE, and others. To answer the above question, we employ a microsimulation model to investigate the cost-effectiveness of various strategies of adding MRI to mammography and CBE (or using MRI alone) for a cohort of women with high risk for breast cancer. Instead of restricting our cohort to a small subset of high-risk women who are $B R C A 1$ or $B R C A 2$ mutation carriers, we chose our study cohort to be consistent with the population targeted in the ACS guidelines for high-risk women: women aged 30 and above with a $25 \%$ lifetime risk or greater of developing breast cancer. This approach allows us to directly assess the cost-effectiveness of screening strategies recommended in the ACS guidelines of MRI screening. We assessed 12 practical screening strategies with different intervals and cessation age of MRI in combinations of biannual, annual, or biennial examinations of mammography and $\mathrm{CBE}$, or none. Together, these combinations offer the opportunity for a comprehensive assessment of screening strategies that add MRI to standard screening programmes using mammography and CBE alone.

\section{MATERIALS AND METHODS}

Overview. Using Monte Carlo simulation programmed in $\mathrm{R}$ (Vienna, Austria; http://www.R-project.org), we generated the natural histories of a large cohort of women at high risk for breast cancer. We modified a previously published model for women at average risk for breast cancer (Shen and Parmigiani, 2005; Ahern and Shen, 2009) to account for differences in age-specific incidence, test characteristics (i.e., sensitivity and specificity), and tumour characteristics that are specific to women at high risk of breast cancer (Chen et al, 2000; Kriege et al, 2004). These risk-specific model inputs and assumptions are required to evaluate the health and economic impact of various screening strategies for this high-risk cohort. We considered 12 screening strategies encompassing different MRI screening intervals (annual vs biennial) and cessation age (50 vs 74) combined with screening mammography plus CBE at intervals of 2,1 , or 0.5 years, or none. We modelled the impact of different screening strategies on costs, survival (life-years), and quality-adjusted life-years (QALYs). Costs in our model captured the entire spectrum of breast cancer care, from breast cancer screening, work-up procedures due to either trueor false-positive examinations, to breast cancer treatments and endof-life care (Figure 1). We utilised estimates from published randomised breast cancer screening trials and observational studies as model inputs.

The model outputs are the expected QALYs and the expected total costs (direct medical costs and indirect costs) per woman, each discounted at $3 \%$ annually beginning at age 30 . Incremental cost-effectiveness ratios (ICERs) were used to compare the screening strategies under consideration (Petitti, 2000; Hunink et al, 2001). Following a standard stepwise approach of comparing multiple strategies in economic evaluation, we rank-ordered the screening strategies by costs in ascending order, and ruled out strategies that are more costly but less effective than an alternative by simple dominance. The ICERs, interpreted as the additional cost required to achieve an increase of one QALY, were calculated for the remaining strategies by dividing the difference in the expected cost by the difference in the expected QALYs compared with the next least-expensive strategy. Strategies with a higher ICER than the ICER in the subsequent pair of comparison were further excluded by extended dominance and the ICER was recalculated after their elimination at each step (Hunink et al, 2001). 


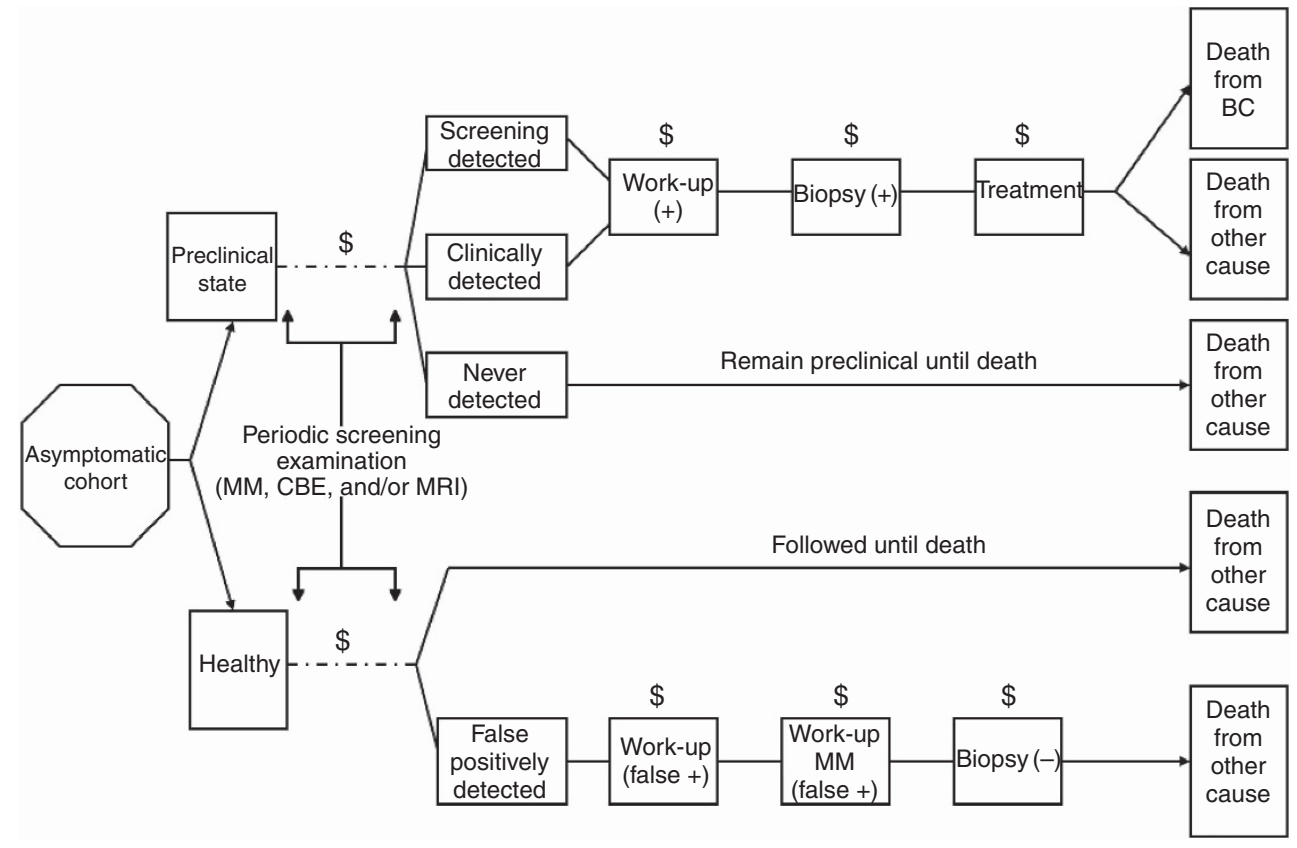

Figure 1. Model structure for evaluating costs of screening, work-up, biopsy, and treatment for breast cancer. ' $\$$ ' represents accrual of costs, and '+' or ' - ' represents a positive or negative test result. Abbreviations: $\mathrm{MM}=$ mammography; $\mathrm{CBE}=$ clinical breast examination; $\mathrm{MRI}=$ magnetic resonance imaging; $\mathrm{BC}=$ breast cancer.

Natural history model. This section provides a brief description of the microsimulation model. Detailed information can be found in our previously published studies (Shen and Parmigiani, 2005; Shen and Parmigiani, 2006; Ahern and Shen, 2009). We generated a birth cohort of 500000 women by Monte Carlo simulation, where each woman's natural history was simulated independently. For women who develop breast cancer according to their agespecific incidence, we generated their natural histories of the disease over time. We assumed four states of the progressive disease in the natural history model (Parmigiani, 1993): diseasefree or asymptomatic, detectable preclinical, clinical, and death. For women with breast cancer, their ages of death were modelled based on age and tumour characteristics at detection, and competing risks.

We calculated age-specific incidence rates for the $25 \%$ lifetime risk cohort by increasing the age-dependent hazard rates for the general population ( $13 \%$ lifetime risk) by a factor independent of age. The ages at onset of preclinical disease are unobservable and were mathematically derived given age-specific incidence of clinical disease and the postulated preclinical sojourn time distribution (Parmigiani, 2002). A random preclinical sojourn time was generated for each woman depending on her age at onset of preclinical disease, using the commonly used exponential distribution with an age-dependent component where the mean sojourn time, $\mu$, depends on age at onset of preclinical disease. Uncertainty was incorporated through an inverse gamma prior for $\mu$ with scale and shape parameters that match the estimated means and s.d. of $1.0(0.7)$ years for women $\leqslant 50$ and $1.9(0.4)$ years for women $>50$ (Chen et al, 2000). For our study cohort (i.e., women with $25 \%$ lifetime risk for breast cancer), the preclinical sojourn times are shorter than those used for the general population, reflecting faster tumour growth (Tilanus-Linthorst et al, 2007). We predicted survival times after diagnosis using a Cox regression model including age, tumour characteristics at diagnosis, and treatment. Clinical parameters in our model are summarised in Table 1.

Screening impacts and diagnostic procedures. The sensitivity and specificity of mammography and CBE differ between the general population and women with high risk for breast cancer.
For high-risk women, sensitivities of mammography and CBE have been shown to be lower, while specificities have been shown to be higher for both screening modalities compared to those for averagerisk women (Kriege et al, 2004). The lower sensitivities may be partially explained by the higher breast density commonly observed among high-risk women who receive screening at a younger age, which contributes to difficult interpretation of the examinations. Following Kriege et al (2004), we modelled age- and tumour-sizespecific sensitivity (Kerlikowske et al, 2000; Weedon-Fekjar et al, 2008) and age-specific specificity for mammography, and constant sensitivity and specificity for CBE (Elmore et al, 2005). We used tumour-size-specific sensitivity and a constant specificity of MRI from Kriege et al (2004), where the sensitivity of MRI is higher than that of mammography given the same tumour size. Uncertainty was accounted for by using a beta distribution for each parameter of sensitivity and specificity. A logit model was used to model the age or tumour-size dependencies. The resulting estimates are similar to the range of sensitivities found in recent publications (Rijnsburger et al, 2010; Heijnsdijk et al, 2012). The overall sensitivity and falsepositive rate associated with a screening strategy that consists of varying combinations of the three examinations were calculated assuming independence of the modalities given the tumour size (Shen et al, 2001). Because sensitivity and specificity of screening mammography are tumour size and/or age dependent, we listed these input parameters as ranges in Table 1; all other parameters are presented as average values.

We used diagnostic mammography as the form of initial workup for positive or abnormal findings from screening examinations, with sensitivity and specificity estimated from the National Cancer Institute Breast Cancer Surveillance Consortium (NCI: BCSC). A biopsy was used to confirm the disease after a positive finding from the initial work-up. If a woman has a symptomatically detected tumour, her disease status would also be confirmed with both a diagnostic mammography and a breast biopsy. Women in the preclinical state who are never diagnosed with breast cancer were assumed to die due to other causes. For women receiving a false-positive mammography, a follow-up mammography is provided 6 months after the last mammography, as in conventional breast cancer screening practice in the United States. 


\begin{tabular}{|c|c|c|c|}
\hline & \multicolumn{2}{|c|}{ Range of values or constant } & \multirow[t]{2}{*}{ Reference } \\
\hline $\begin{array}{l}\text { Age-specific incidence } \\
25 \% \text { Lifetime risk cohort }\end{array}$ & $\begin{array}{l}30 \leqslant \text { age }<50 \\
0.06-0.26 \%\end{array}$ & $\begin{array}{l}50 \leqslant \text { age }<90 \\
0.32-0.74 \%\end{array}$ & \\
\hline Sojourn time (mean (s.d.)) & age $\leqslant 50: 1.0(0.7)$ & age > 50: $1.9(0.4)$ & Chen et al, 2000 \\
\hline $\begin{array}{l}\text { MM sensitivity (age- and tumour size-dependent) } \\
\text { Tumour size }=1 \mathrm{~cm} \\
\text { Tumour size }=0.05 \mathrm{~cm} \\
\text { MM specificity (age dependent) }\end{array}$ & $\begin{array}{l}30 \leqslant \text { age }<50 \\
0.307-0.491 \\
0.034-0.071 \\
0.922-0.967\end{array}$ & $\begin{array}{l}50 \leqslant \text { age }<90 \\
0.501-0.832 \\
0.074-0.283 \\
0.968-0.995\end{array}$ & Kriege et al, 2004 \\
\hline $\begin{array}{l}\text { CBE sensitivity } \\
\text { CBE specificity }\end{array}$ & $\begin{array}{l}0.178 \\
0.981\end{array}$ & & $\begin{array}{l}\text { Kriege et al, } 2004 \\
\text { Kriege et al, } 2004\end{array}$ \\
\hline $\begin{array}{l}\text { MRI sensitivity (tumour size-dependent) } \\
\text { Tumour size }=1 \mathrm{~cm} \\
\text { Tumour size }=0.05 \mathrm{~cm} \\
\text { MRI specificity }\end{array}$ & $\begin{array}{l}0.710 \\
0.250 \\
0.900\end{array}$ & & $\begin{array}{l}\text { Kriege et al, } 2004 \\
\text { Kriege et al, 2004; Elmore et al, } 2005\end{array}$ \\
\hline $\begin{array}{l}\text { Diagnostic MM sensitivity } \\
\text { Diagnostic MM specificity }\end{array}$ & $\begin{array}{l}0.880 \\
0.900\end{array}$ & & National Cancer Institute: Breast Cancer Surveillance Consortium, 2014 \\
\hline
\end{tabular}

Simulation of survival and QALY following treatment. Tumour characteristics at diagnosis determined the type of treatment patients received in our model (NIH Consensus Statement. Adjuvant Therapy for Breast Cancer). We predicted the number of nodes at diagnosis using a Poisson linear model given age and tumour size based on Surveillance, Epidemiology, and End Results (SEER) registry data (Ries et al, 2005). We simulated ER status independently, assuming $70 \%$ of diagnosed cases to be ER positive (Fisher et al, 1998).

We determined the stage of disease using the tumour-nodemetastasis staging system (Singletary et al, 2002) given tumour size and the predicted number of nodes. Given disease stage at diagnosis, patients received breast conserving surgery or mastectomy with or without radiation according to recent studies of breast cancer treatment patterns (Barlow et al, 2001; Shen et al, 2007). The treatments of tamoxifen, chemotherapy, or a combination were based on dissemination patterns observed in the USA; the pattern varied by age, stage of disease, and ER status at diagnosis (Mariotto et al, 2006). We obtained the treatment pattern of trastuzumab among chemotherapy users from a recent analysis of SEER-Medicare database (Chavez-MacGregor et al, 2013).

Covariate coefficients for age, primary tumour size, and number of nodes at diagnosis in the Cox regression used for the baseline predictive survival model were estimated based on a combined analysis of four Cancer and Leukemia Group B trials (Wood et al, 1985; Wood et al, 1994; Perloff et al, 1996; Parmigiani, 2002). We then used the hazard reductions to model the treatment effects of tamoxifen for ER-positive patients, chemotherapy and additional trastuzumab for HER2-positive patients on survival (Mariotto et al, 2006; Dahabreh et al, 2008). If a woman's estimated breast cancer survival time was shorter than her simulated natural lifetime according to actuarial tables for the 1960 birth cohort from the U.S. Census Bureau, she would be assumed to have died of breast cancer; otherwise she would die from a competing cause.

To estimate QALY, we incorporated health utilities associated with the negative effects of breast cancer treatments (i.e., surgery, radiation, chemotherapy, and hormonal therapy) and terminal disease stage (Tengs and Wallace, 2000). Utilities for the terminal stage of life associated with causes other than breast cancer were estimated using a weighted average of quality-of-life weights for the top three causes of death in women in the United States (Centers for Disease Control and
Table 2. Health utility used in the simulation analysis

\begin{tabular}{|l|c|l|}
\hline Intervention & Health utility & $\begin{array}{l}\text { Duration of utility } \\
\text { reduction }\end{array}$ \\
\hline Breast surgery & 0.87 & 3 Months \\
\hline Radiation & 0.80 & 3 Months \\
\hline Chemotherapy & 0.74 & 1 Year \\
\hline Tamoxifen & 0.99 & 5 Years \\
\hline Terminal stage (breast cancer) & 0.29 & Last 3 months \\
\hline Terminal stage (other ${ }^{\text {a }}$ ) & 0.375 & Last 3 months \\
\hline $\begin{array}{l}\text { a Estimated using a weighted average of weights for heart disease, cerebrovascular disease, } \\
\text { and lung cancer in women. }\end{array}$ \\
\hline
\end{tabular}

Prevention: Breast cancer statistics) (Table 2). These utility values were weighted using the duration of the respective treatment or disease stage, to calculate QALY for each woman.

Costs. In our model, costs captured the entire spectrum of breast cancer care. Table 3 summarises the unit cost of health care resources incorporated in our estimation of direct medical costs, including screening mammography, CBE, MRI, diagnostic mammography, as well as biopsy and treatments (Plevritis et al, 2006; Yabroff et al, 2008; Allen, 2010). For the treatment of breast cancer, we included costs by treatment phase (initial, continuing, and terminal) and cancer stage (local, regional, and distant) (Yabroff et al, 2008; Riley and Lubitz, 2010). In addition, we added costs associated with 5-year prescriptions of tamoxifen for women who are ER positive (Allen, 2010) and trastuzumab costs for women who are HER2 positive (Shih et al, 2010). Indirect costs from lost productivity for women who die prematurely from breast cancer (i.e., mortality costs resulting from lost wages) were estimated using age-specific wage rates for female workers in the labour market of the United States (Day and Newburger, 2002). All costs were normalised to 2012 US dollars using the medical care component of the consumer price index (Bureau of Labor Statistics: Consumer Price Index). 


\begin{tabular}{|c|c|c|c|c|}
\hline Cost components & & & $\begin{array}{c}\text { Cost } \\
(\$)\end{array}$ & \\
\hline \multicolumn{5}{|l|}{ Screening-related costs } \\
\hline $\begin{array}{l}\text { Mammography } \text { (bilateral) }^{\mathbf{a}} \\
\text { Clinical breast examination }^{\mathbf{a}} \\
\text { Magnetic resonance imaging }^{\text {a }} \\
\text { Diagnostic mammography } \\
\text { (unilateral) }^{\mathbf{a}} \\
\text { Breast biopsy, }^{\mathrm{a}, \mathrm{b}}\end{array}$ & & & $\begin{array}{c}142 \\
38 \\
728 \\
171 \\
\\
656\end{array}$ & \\
\hline \multicolumn{5}{|l|}{ Treatment-related costs } \\
\hline $\begin{array}{l}\text { Tamoxifen } / 5 \text { years }{ }^{c} \\
\text { Trastuzumab as adjuvant therapy/ } \\
\text { year }^{d} \\
\text { Trastuzumab for metastatic BC } \\
\text { Annual costs by phase and stage }\end{array}$ & $\begin{array}{l}\text { Treatment phase } \\
\text { (annual) }^{\mathbf{f}} \\
\text { Initial } \\
\text { Continuing } \\
\text { Terminal }\end{array}$ & $\begin{array}{c}\text { Local } \\
13057 \\
1607 \\
35340\end{array}$ & $\begin{array}{c}1281 \\
60087 \\
34692 \\
\\
\text { Regional } \\
\\
24685 \\
1607 \\
41831 \\
4008\end{array}$ & $\begin{array}{c}\text { Distant } \\
38125 \\
1607 \\
58673\end{array}$ \\
\hline \multicolumn{5}{|c|}{ 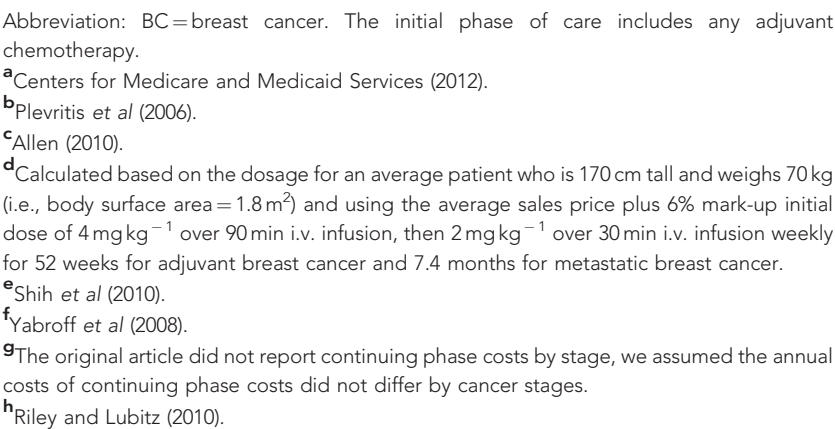 } \\
\hline
\end{tabular}

Sensitivity analysis. We conducted sensitivity analyses to assess the robustness of our conclusions against key assumptions regarding the modelling parameters, such as changes in the lifetime risk (increase to $50 \%$ and $75 \%$ ) and cost of MRI. Because of the high cost of MRI, a natural question that arises is whether reducing the cost of MRI would alter the cost-effectiveness of screening strategies involving MRI. Thus, we reduced the cost of MRI by $50 \%$ and $70 \%$, which reduces the MRI cost from seven times to just over twice the cost of mammography, respectively.

\section{RESULTS}

Table 4 shows the 12 screening strategies with various combinations of MRI and mammography plus CBE for women between ages 30 and 74, and who have a 25\% lifetime risk of breast cancer at birth. MRI, at either an annual or biennial frequency, is included in every strategy, since our goal is to compare alternative approaches to timing MRIs and combining them with other screening modalities. The tradeoff plot for the $25 \%$ lifetime risk cohort is provided in Figure 2, which corresponds to Table 4. The dominated strategies are those that lie above the efficiency frontier. After excluding strategies that were dominated or extendedly dominated, four strategies remained in the cost-effectiveness comparison: strategy A that gives only MRI every 2 years, strategy $B$ that staggers MRI and mammography + CBE every year and strategies $\mathrm{F}$ and $\mathrm{L}$, which give mammography and CBE every 6 months with MRI every other year (strategy F) or MRI every year (strategy L). Compared to strategy A, the cheapest strategy, strategy $\mathrm{B}$ gained 0.0233 QALYs ( $~ 8.5$ quality-adjusted days) costing $\$ 58400$ per QALY gained. Strategy F gained 0.0204 QALYs $(<8$ quality-adjusted days) compared to strategy $\mathrm{B}$, resulting in an ICER of \$323700 per QALY. Finally, strategy L gained 0.0009 QALY (less than one quality-adjusted day) compared to strategy F, costing over an additional $\$ 8.8$ million per QALY. Therefore, if one has to adopt the ICER threshold of $\$ 100000 / \mathrm{Q} A L Y$, frequently chosen in recent literature (Ubel et al, 2003), the recommended strategy would be to stagger MRI and mammography plus CBE every year (i.e., strategy B).

Sensitivity analysis. We explored six scenarios in our sensitivity analyses, including cohorts at increased lifetime risk $(50 \%$ and $75 \%)$ and cost reductions of MRI (50\% and $70 \%$ reduction) in the two high-risk cohorts: those with $25 \%$ vs $50 \%$ lifetime risk (Table 5 and Figures $3 \mathrm{~A}-\mathrm{F}$ ). With biennial MRI alone (strategy A) as our base of comparison (i.e., the lowest-cost strategy), strategy $\mathrm{B}$ remained the recommended strategy after reducing the cost of MRI by $50 \%$ or $70 \%$ for the cohort of women with $25 \%$ lifetime risk. As the lifetime risk increased to $50 \%$, strategy B was highly costeffective when compared to strategy A, yielding ICER $\sim \$ 21000 /$ QALY with current MRI cost and $~ \$ 26000 /$ QALY with $50 \%$ reduction in MRI cost. When MRI cost was reduced by $70 \%$ for lifetime risk of $50 \%$ or higher, strategy J (i.e., staggering MRI and mammography $+\mathrm{CBE}$ every 6 months) became the recommended strategy from our cost-effectiveness analysis. When the lifetime risk of breast cancer was increased to $75 \%$, the recommended strategy became biennial MRI combined with mammography $+\mathrm{CBE}$ every 6 months (i.e., strategy F).

\section{DISCUSSION}

Magnetic resonance imaging screening, because of its higher sensitivity compared to mammography, is commonly considered for women at high risk for breast cancer in the United States and many European countries. Although it may be beneficial to give high-risk women routine MRI examinations in addition to their regular mammography and $\mathrm{CBE}$ examinations, the high cost of MRI, combined with its lower specificity, raise the question of the optimal use of MRI in breast cancer screening programmes targeted at high-risk women. We employed a microsimulation model to answer this question.

Our analysis indicates that if MRI were to be integrated into the screening programmes for high-risk women, it would have to be combined with mammography plus CBE either concurrently or sequentially (i.e., staggered). Among all the screening strategies and scenarios of sensitivity analysis explored in our study, none supported the use of MRI as the sole screening modality for these women. In most cases, the strategy recommended from our costeffectiveness analysis was to stagger MRI and mammography plus $\mathrm{CBE}$ every year (i.e., strategy B), although we found that at the current cost of MRI, a more frequent schedule of mammography plus CBE (combined with biennial MRI; i.e., strategy F) was costeffective for women with a $75 \%$ or higher lifetime risk of breast cancer. We also found that if the MRI cost was substantially reduced $(\geqslant 70 \%)$, annual MRI staggered by annual mammography $+\mathrm{CBE}$ with 6 months interval in between (i.e., strategy J) was cost-effective for women with lifetime risk of $50 \%$ or greater. In the context of ACS guidelines for MRI screening in breast cancer, strategy $\mathrm{J}$ is especially interesting because the guidelines do not provide specific instructions on how to integrate 


\begin{tabular}{|c|c|c|c|c|c|c|c|}
\hline Strategy & MM intv(age) & CBE intv(age) & MRI intv(age) & Total cost (\$) & QALYs (years) & $\begin{array}{c}\text { Increm } \\
\text { QALYs gained }\end{array}$ & ICER \\
\hline$A$ & & & $2(30-74)$ & 36500 & 53.5215 & - & - \\
\hline B & $2(30-74)$ & $2(30-74)$ & $2(31-74)$ & 37900 & 53.5448 & 0.0233 & 58400 \\
\hline C & $1(30-74)$ & $1(30-74)$ & $2(30-74)$ & 40600 & 53.5464 & - & - \\
\hline$D$ & $1(30-74)$ & $1(30-74)$ & $1(30-50)$ & 43300 & 53.5490 & - & - \\
\hline$E$ & & & $1(30-74)$ & 44200 & 53.5455 & - & - \\
\hline $\mathrm{F}$ & $0.5(30-74)$ & $0.5(30-74)$ & $2(30-74)$ & 44700 & 53.5659 & 0.0204 & 323700 \\
\hline G & $1(30-50), 2$ (51-74) & $1(30-50), 2$ (51-74) & 1 (30-50), 2 (51-74) & 45500 & 53.5407 & - & - \\
\hline $\mathrm{H}$ & $1(30-74)$ & $1(30-74)$ & $1(30-50), 2$ (51-74) & 46200 & 53.5472 & - & - \\
\hline 1 & $2(30-74)$ & $2(30-74)$ & $1(30-74)$ & 46600 & 53.5480 & - & - \\
\hline J & $1(30-74)$ & $1(30-74)$ & $1(30.5-74)$ & 48100 & 53.5662 & - & - \\
\hline K & $1(30-74)$ & $1(30-74)$ & $1(30-74)$ & 48900 & 53.5510 & - & - \\
\hline L & $0.5(30-74)$ & $0.5(30-74)$ & $1(30-74)$ & 53000 & 53.5668 & 0.0009 & 8833800 \\
\hline
\end{tabular}

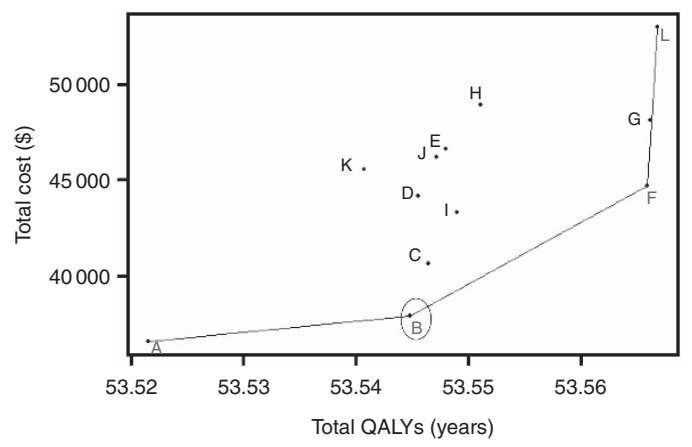

Figure 2. Tradeoff plot for the $25 \%$ lifetime risk cohort. $x$-Axis is mean quality-adjusted life-years. y-Axis is mean total cost in 2012 US dollars. Dominated strategies lie above the cost-effectiveness frontier connecting the non-dominated alternatives.

MRI into mammography screening, such a strategy, which staggers the screening modalities every 6 months, is suggested as one possibility (Saslow et al, 2007). The potential advantage of this strategy is that it may reduce the rate of interval cancers by offering alternate screening every 6 months, affording earlier detection of more treatable tumours. However, based on our analysis, this strategy is only justified when there is a substantial reduction in MRI cost $(\geqslant 70 \%)$ compared to current cost and the lifetime risk of breast cancer was $50 \%$ or greater.

In contrast to previous studies that focused on BRCA1/2 mutation carriers, our study focuses on a more general high-risk population of patients with a $25 \%$ or greater lifetime risk of developing breast cancer, which makes our study more applicable to provide screening recommendations to the general high-risk population. Restricting cost-effectiveness analysis to genetically susceptible women offers limited information to decision makers who are making policy recommendations for all high-risk women because breast cancer incidence in BRCA1/2 mutation carriers is just $\sim 4 \%$ per annum in the age group of 40-49 years (Antoniou et $a l, 2003)$. In addition, ongoing efforts have been made to improve existing prediction models for women at high risk using risk factors other than $B R C A$ mutational status that can be obtained during routine screening examinations (Barlow et al, 2006; Cummings et al, 2009). All of this evidence supports the importance of assessing the cost-effectiveness of MRI in a broader group of patients than BRCA1/2 mutation carriers.

Besides expanding our study beyond women with BRCA1/2 mutation carriers, our study differs from prior cost-effectiveness analyses of MRI in which we include CBE as a part of the screening programmes under examination since $\mathrm{CBE}$ is commonly used in combination with mammography in screening practice. Our study is also unique in that it examines a more comprehensive list of screening strategies in the context of integrating MRI to existing screening programmes and incorporates detailed modelling of disease progression without assuming a screening benefit on survival. Instead, the potential survival benefit is reflected via stage shift at diagnosis given each individual's nodal status, tumour size, and sojourn time distribution. We also model the distribution of treatment according to simulated patient characteristics and treatment patterns reported from real-world data.

Despite the differences in risk profiles and modelling approaches among the studies, there is agreement that the use of MRI annually is unlikely to be cost-effective for the general highrisk cohort, but more likely to be cost-effective for certain high-risk subgroups such as those with $>45 \%$ lifetime risk of developing breast cancer, $B R C A 1 / 2$ mutation carriers, or very specifically selected age groups such as ages 35-54 (Plevritis et al, 2006; Moore et al, 2009; Saadatmand et al, 2013). Building upon previous findings that adding MRI to mammography and CBE may be costeffective for high-risk women, our study explored the optimal way of integrating MRI into current practice in this cohort of women. We asked if MRI has to be integrated into the screening programmes for high-risk women and if at a minimum we are to offer MRI alone every other year, are other strategies with more frequent use of MRI and/or mammography + CBE more costeffective than this lowest-cost strategy? Results of our analyses suggest that, for the women at 20-25\% lifetime risk considered in the ACS guidelines, the current test characteristics and cost structure of MRI do not justify more frequent use of MRI other than the strategy that staggers MRI and mammography plus CBE every year. 
Table 5. Results of sensitivity analyses

\begin{tabular}{|c|c|c|c|c|c|}
\hline & Strategy $^{a}$ & Total cost (\$) & QALYs (years) & Increm QALYs gained & ICER \\
\hline Base case $(25 \%$ LR) & $\mathrm{B}$ & 37900 & 53.5448 & $0.0232^{\mathrm{b}}$ & $58400^{b}$ \\
\hline $25 \% \mathrm{LR}, 50 \%$ reduction in MRI cost & B & 33900 & 53.5448 & $0.0232^{b}$ & $67400^{b}$ \\
\hline $25 \% \mathrm{LR}, 70 \%$ reduction in MRI cost & B & 32300 & 53.5448 & $0.0232^{b}$ & $71000^{b}$ \\
\hline $50 \%$ LR & B & 55300 & 53.2086 & $0.0412^{b}$ & $20700^{b}$ \\
\hline $50 \% \mathrm{LR}, 50 \%$ reduction in MRI cost & B & 51500 & 53.2086 & $0.0412^{b}$ & $25700^{b}$ \\
\hline $50 \% \mathrm{LR}, 70 \%$ reduction in MRI cost & $\mathrm{J}$ & 53500 & 53.2531 & $0.0392^{c}$ & $84400^{\circ}$ \\
\hline $75 \%$ LR & $\mathrm{F}$ & 79900 & 52.8321 & $0.0749^{d}$ & $62800^{\circ}$ \\
\hline
\end{tabular}

Abbreviations: ICER = incremental cost-effectiveness ratio (incremental cost/incremental QALYs gained compared to next least-expensive strategy); increm =incremental; LR = lifetime risk; $M R I=$ magnetic resonance imaging; $\mathrm{QALY}=$ mean total expected quality-adjusted life-years per woman. Total cost is the mean total cost per woman in the complete cohort, rounded to the nearest $\$ 100$. Strategies listed are those with the lowest ICER compared to the cheapest strategy (strategy A) for each of the investigated scenarios.

${ }^{\text {a }}$ Recommended strategy based on ICER threshold of $\$ 100000 / Q A L Y$.

${ }^{\mathbf{b}}$ Compared to strategy A.

${ }^{\mathrm{c}}$ Compared to strategy E.

${ }^{\mathrm{d}}$ Compared to strategy B.

A

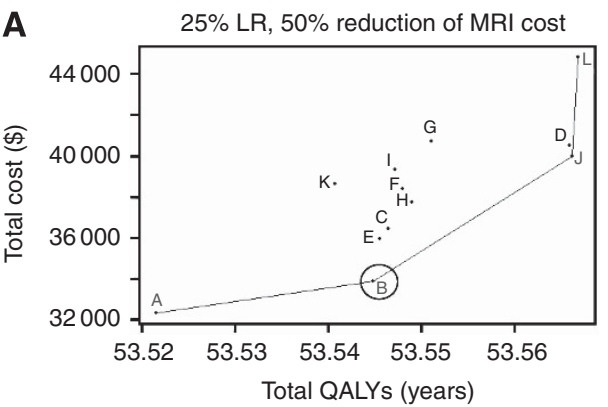

C

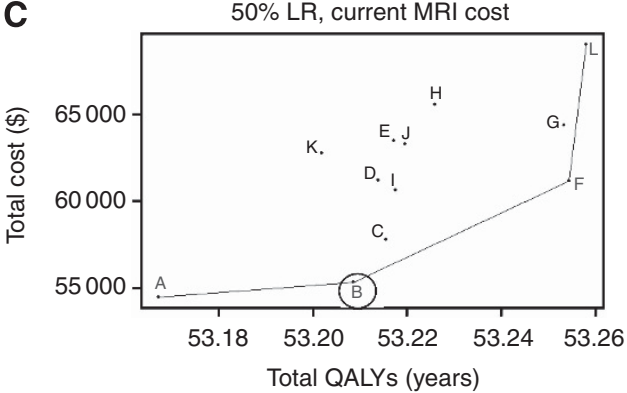

E

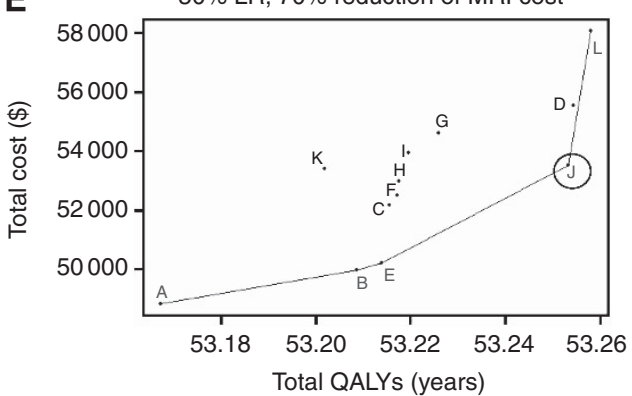

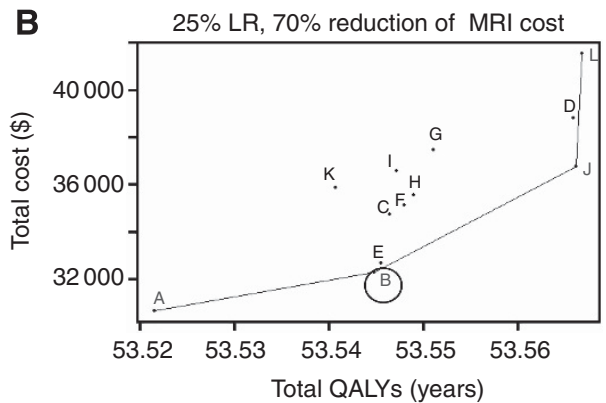

D $\quad 50 \% \mathrm{LR}, 50 \%$ reduction of $\mathrm{MRI}$ cost

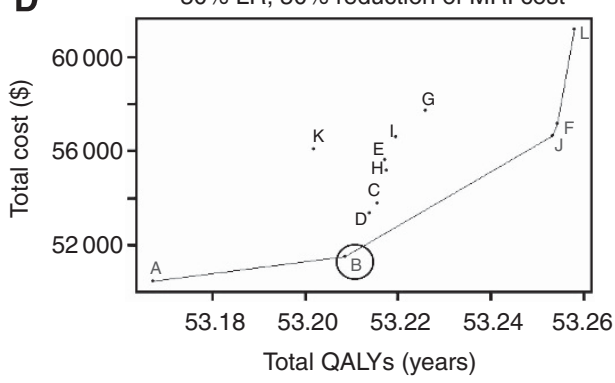

$\mathbf{F}$

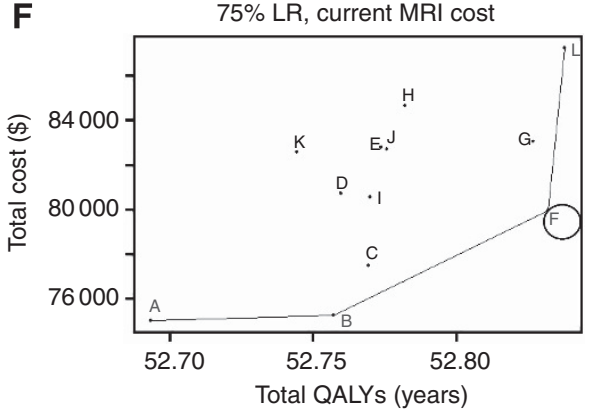

Figure 3. Tradeoff plots for six scenarios of sensitivity analyses. (A) $25 \% \mathrm{LR}$ and $50 \%$ reduction of MRI cost; (B) $25 \% \mathrm{LR}$ and $70 \%$ reduction of MRI cost; (C) 50\% LR and current MRI cost; (D) 50\% LR and 50\% reduction of MRI cost; (E) $50 \%$ LR and $70 \%$ reduction of MRI cost; and (F) $75 \%$ LR and current MRI cost. $x$-Axis is mean quality-adjusted life-years. $y$-Axis is mean total cost in 2012 US dollars. Dominated strategies lie above the costeffectiveness frontier connecting the non-dominated alternatives. Abbreviation: $L R=$ lifetime risk.

Interestingly, the same conclusion was reached in a recent costeffectiveness analysis from authors in the Netherlands that focused on women with familial risk for breast cancer (Saadatmand et al,
2013), defined as women with a lifetime risk between $15 \%$ and $50 \%$ in their model - a range in line with the $25 \%$ lifetime risk in our base case analysis. However, this similarity needs to be interpreted 
with caution because of the difference in the comparators that formed the basis of the comparison, as well as difference in cost structure between countries. Specifically, the basis of comparison in Saadatmand et al (2013) was biennial mammography screening from age 50 to 75 years, which is the current protocol of the Dutch nationwide breast cancer screening programme, whereas our finding was based on the comparison to MRI alone every other year. In addition, the 'staggering' strategy that was found to be cost-effective in their study only applied to women between 35 and 50 years of age (women were reverted back to biennial mammography after 50 years), while our model applied the 'staggering' strategy to high-risk women between age 30 and 74 years. Furthermore, the cost of MRI was set to be much lower in the Netherlands than in the USA (\$485 vs \$728). All these considerations make it difficult to directly compare our study with Saadatmand et al (2013).

This study has several limitations. First, we do not model the survival outcomes associated with all recent therapeutic innovations, such as third-generation endocrine therapies, and we assume full compliance in terms of screening schedule. We did, however, incorporated the survival benefit according to recent treatment patterns for chemotherapies including trastuzumab, and the corresponding costs in our model. Second, the physical and emotional effects arising from either screening or from unnecessary procedures following false positives were not accounted for. However, because health utility decrements associated with these events often apply to a relative short time interval, these factors are unlikely to bias our finding in favour of any particular screening strategy and our ranking of strategies is likely to be robust. Third, overdiagnosis was not assessed in this study. By expanding our model to include non-invasive DCIS, we may quantify overdiagnosis resulting from screening programmes in a future study. Lastly, while clinical trials for assessing MRI in a high-risk group for breast cancer are currently underway (ClinicalTrials.gov: A service of the U.S. National Institutes of Health), there are no large randomised, controlled clinical trials that have been completed assessing the use of MRI as an additional screening modality for healthy women at high-risk for breast cancer. We thus relied on information available in the literature for our data inputs and models. As new information becomes available in the future, we can update our input parameters in the model accordingly.

Despite these limitations, our study provides evidence that the cost-effectiveness of adding routine MRI to mammography and $\mathrm{CBE}$ screening in women with increased risk for breast cancer will depend on the level of lifetime risk of the woman, the cost of MRI, as well as how often and in what combination MRI is implemented. Although the ACS recommendations are not explicit on how MRI should be incorporated into current practice, our findings suggests that staggering MRI with mammography/CBE with 1-year interval in between is likely to be a cost-effective screening strategy for women with a higher risk of breast cancer. From a societal perspective, the high costs associated with the low specificity of MRI are currently limiting factors for the annual schedule of MRI recommended by the ACS.

\section{ACKNOWLEDGEMENTS}

This work was supported by the National Institutes of Health (P30 CA125123) to CHA; the National Institutes of Health (R03HG004 055, R21-CA165092, and RC1CA145799) to YCS; the National Institutes of Health (5P30 CA006516-46) to GP; and the National Institutes of Health (R01-CA07466, R21-CA165092, and P30 CA016672) to YS.

\section{REFERENCES}

Afonso NM (2009) Women at high risk for breast cancer-what the primary care provider needs to know. J Am Board Fam Med 22: 43-50.

Ahern CH, Shen Y (2009) Cost-effectiveness analysis of mammography and clinical breast examination strategies: a comparison with current guidelines. Cancer Epidemiol Biomarkers Prev 18(3): $718-725$.

Allen JM (2010) Economic/societal burden of metastatic breast cancer: a US perspective. Am J Manag Care 16(9): 697-704.

American Cancer Society: Detailed Guide: breast cancer. Can breast cancer be found early? http://www.cancer.org/docroot/CRI/content/ CRI_2_4_3X_Can_breast_cancer_be_found_early_5.asp.

Antoniou A, Pharoah PD, Narod S, Risch HA, Eyfjord JE, Hopper JL, Loman N, Olsson H, Johannsson O, Borg A, Pasini B, Radice P, Manoukian S, Eccles DM, Tang N, Olah E, Anton-Culver H, Warner E, Lubinski J, Gronwald J, Gorski B, Tulinius H, Thorlacius S, Eerola H, Nevanlinna H, Syrjakoski K, Kallioniemi OP, Thompson D, Evans C, Peto J, Lalloo F, Evans DG, Easton DF (2003) Average risks of breast and ovarian cancer associated with BRCA1 or BRCA2 mutations detected in case Series unselected for family history: a combined analysis of 22 studies. Am J Hum Genet 72(5): 1117-1130.

Barlow WE, Taplin SH, Yoshida CK, Buist DS, Seger D, Brown M (2001) Cost comparison of mastectomy versus breast-conserving therapy for early-stage breast cancer. J Natl Cancer Inst 93(6): 447-455.

Barlow WE, White E, Ballard-Barbash R, Vacek PM, Titus-Ernstoff L, Carney PA, Tice JA, Buist DS, Geller BM, Rosenberg R, Yankaskas BC, Kerlikowske K (2006) Prospective breast cancer risk prediction model for women undergoing screening mammography. J Natl Cancer Inst 98(17): 1204-1214.

Bureau of Labor Statistics: Consumer Price Index. http://data.bls.gov/CPI/. Centers for Disease Control and Prevention: Breast cancer statistics. http:// www.cdc.gov/cancer/breast/statistics/.

Centers for Medicare and Medicaid Services (2012) 2012 National physician fee schedule relative value file. http://cms.gov/Medicare/Medicare-Fee-forService-Payment/PhysicianFeeSched/PFS-Relative-Value-Files.htmlAccessed 27 January 2014.

Chavez-MacGregor M, Zhang N, Buchholz TA, Zhang Y, Niu J, Elting L, Smith BD, Hortobagyi GN, Giordano SH (2013) Trastuzumab-related cardiotoxicity among older patients with breast cancer. J Clin Oncol 31(33): 4222-4228.

Chen TH, Kuo HS, Yen MF, Lai MS, Tabar L, Duffy SW (2000) Estimation of sojourn time in chronic disease screening without data on interval cases. Biometrics 56(1): 167-172.

ClinicalTrials.gov: A service of the U.S. National Institutes of Health. http:// clinicaltrials.gov/ct2/results?term $=$ Breast + MRI + High + Risk.

Cott Chubiz JE, Lee JM, Gilmore ME, Kong CY, Lowry KP, Halpern EF, McMahon PM, Ryan PD, Gazelle GS (2013) Cost-effectiveness of alternating magnetic resonance imaging and digital mammography screening in BRCA1 and BRCA2 gene mutation carriers. Cancer 119(6): 1266-1276.

Cummings SR, Tice JA, Bauer S, Browner WS, Cuzick J, Ziv E, Vogel V, Shepherd J, Vachon C, Smith-Bindman R, Kerlikowske K (2009) Prevention of breast cancer in postmenopausal women: approaches to estimating and reducing risk. J Natl Cancer Inst 101(6): 384-398.

Dahabreh IJ, Linardou H, Siannis F, Fountzilas G, Murray S (2008) Trastuzumab in the adjuvant treatment of early-stage breast cancer: a systematic review and meta-analysis of randomized controlled trials. Oncologist 13(6): 620-630.

Day JC, Newburger EC (2002) The big payoff: educational attainments and synthetic estimates of work-life earnings, 2002. http://www.census.gov/ prod/2002pubs/p23-210.pdf.

de Bock GH, Vermeulen KM, Jansen L, Oosterwijk JC, Siesling S, Dorrius MD, Feenstra T, Houssami N, Greuter MJ (2013) Which screening strategy should be offered to women with BRCA1 or BRCA2 mutations? A simulation of comparative cost-effectiveness. Br J Cancer 108(8): 1579-1586.

Elmore JG, Armstrong K, Lehman CD, Fletcher SW (2005) Screening for breast cancer. JAMA 293(10): 1245-1256. 
Fisher B, Costantino JP, Wickerham DL, Redmond CK, Kavanah M, Cronin WM, Vogel V, Robidoux A, Dimitrov N, Atkins J, Daly M, Wieand S, Tan-Chiu E, Ford L, Wolmark N (1998) Tamoxifen for prevention of breast cancer: report of the National Surgical Adjuvant Breast and Bowel Project P-1 Study. J Natl Cancer Inst 90(18): 1371-1388.

Heijnsdijk EA, Warner E, Gilbert FJ, Tilanus-Linthorst MM, Evans G, Causer PA, Eeles RA, Kaas R, Draisma G, Ramsay EA, Warren RM, Hill KA, Hoogerbrugge N, Wasser MN, Bergers E, Oosterwijk JC, Hooning MJ, Rutgers EJ, Klijn JG, Plewes DB, Leach MO, de Koning HJ (2012) Differences in natural history between breast cancers in BRCA1 and BRCA2 mutation carriers and effects of MRI screening-MRISC, MARIBS, and Canadian studies combined. Cancer Epidemiol Biomarkers Prev 21(9): 1458-1468.

Hunink M, Glasziou P, Siegel J, Weeks J, Pilskin J, Elstein A, Weinstein M (2001) Decision Making in Health and Medicine: Integrating Evidence and Values. Cambridge University Press: New York, NY.

Kerlikowske K, Carney PA, Geller B, Mandelson MT, Taplin SH, Malvin K, Ernster V, Urban N, Cutter G, Rosenberg R, Ballard-Barbash R (2000) Performance of screening mammography among women with and without a first-degree relative with breast cancer. Ann Intern Med 133(11): 855-863.

Kriege M, Brekelmans CT, Boetes C, Besnard PE, Zonderland HM, Obdeijn IM, Manoliu RA, Kok T, Peterse H, Tilanus-Linthorst MM, Muller SH, Meijer S, Oosterwijk JC, Beex LV, Tollenaar RA, de Koning HJ, Rutgers EJ, Klijn JG (2004) Efficacy of MRI and mammography for breast-cancer screening in women with a familial or genetic predisposition. $N$ Engl J Med 351(5): 427-437.

Kriege M, Brekelmans CT, Obdeijn IM, Boetes C, Zonderland HM, Muller SH, Kok T, Manoliu RA, Besnard AP, Tilanus-Linthorst MM, Seynaeve C, Bartels CC, Kaas R, Meijer S, Oosterwijk JC, Hoogerbrugge N, Tollenaar RA, Rutgers EJ, de Koning HJ, Klijn JG (2006) Factors affecting sensitivity and specificity of screening mammography and MRI in women with an inherited risk for breast cancer. Breast Cancer Res Treat 100(1): 109-119.

Kuhl CK, Schrading S, Leutner CC, Morakkabati N, Trog D, Schmutzler R, Schild HH (2003) Surveillance of "high risk" women with proven or suspected familial (hereditary) breast cancer: first mid-term results of a multi-modality clinical screening trial. Proc Am Soc Clin Oncol 22: 2.

Leach MO, Boggis CR, Dixon AK, Easton DF, Eeles RA, Evans DG, Gilbert FJ, Griebsch I, Hoff RJ, Kessar P, Lakhani SR, Moss SM, Nerurkar A, Padhani AR, Pointon LJ, Thompson D, Warren RM (2005) Screening with magnetic resonance imaging and mammography of a UK population at high familial risk of breast cancer: a prospective multicentre cohort study (MARIBS). Lancet 365(9473): 1769-1778.

Mariotto AB, Feuer EJ, Harlan LC, Abrams J (2006) Dissemination of adjuvant multiagent chemotherapy and tamoxifen for breast cancer in the United States using estrogen receptor information: 1975-1999. J Natl Cancer Inst Monogr 36: 7-15.

Moore SG, Shenoy PJ, Fanucchi L, Tumeh JW, Flowers CR (2009) Cost-effectiveness of MRI compared to mammography for breast cancer screening in a high risk population. BMC Health Serv Res 9: 9.

National Cancer Institute: Breast Cancer Surveillance Consortium. http://breastscreening.cancer.gov/data/benchmarks/diagnostic/ tableSensSpec.html.

NIH Consensus Statement (2000) Adjuvant therapy for breast cancer 17(4): 1-23.

Parmigiani G (1993) On optimal screening ages. J Am Stat Assoc 88(422): $622-628$.

Parmigiani G (2002) Modeling in Medical Decision Making. John Wiley and Sons, Ltd: West Sussex, England.

Pataky R, Armstrong L, Chia S, Coldman AJ, Kim-Sing C, McGillivray B, Scott J, Wilson CM, Peacock S (2013) Cost-effectiveness of MRI for breast cancer screening in BRCA1/2 mutation carriers. BMC Cancer 13: 339 .

Perloff M, Norton L, Korzun AH, Wood WC, Carey RW, Gottlieb A, Aust JC, Bank A, Silver RT, Saleh F, Canellos GP, Perry MC, Weiss RB, Holland JF (1996) Postsurgical adjuvant chemotherapy of stage II breast carcinoma with or without crossover to a non-cross-resistant regimen: a Cancer and Leukemia Group B study. J Clin Oncol 14(5): $1589-1598$.

Petitti D (2000) Meta-analysis, Decision Analysis, and Cost-effectiveness Analysis. 2nd edn. Oxford University Press, Inc.: New York, NY.

Plevritis SK, Kurian AW, Sigal BM, Daniel BL, Ikeda DM, Stockdale FE, Garber AM (2006) Cost-effectiveness of screening BRCA1/2 mutation carriers with breast magnetic resonance imaging. JAMA 295(20): 2374-2384.

Ries LAG, Eisner MP, Kosary CL, Hankey BA, Clegg L, Mariotto A, Feuer EJ, Edwards BK (2005) SEER Cancer Statistics Review, 1975-2002. National Cancer Institute: Bethesda, MDhttp://seer.cancer.gov/csr/1975_2002/ based on November 2004 SEER data submission, posted to the SEER web site 2005 .

Rijnsburger AJ, Obdeijn IM, Kaas R, Tilanus-Linthorst MM, Boetes C, Loo CE, Wasser MN, Bergers E, Kok T, Muller SH, Peterse H, Tollenaar RA, Hoogerbrugge N, Meijer S, Bartels CC, Seynaeve C, Hooning MJ, Kriege M, Schmitz PI, Oosterwijk JC, de Koning HJ, Rutgers EJ, Klijn JG (2010) BRCA1-associated breast cancers present differently from BRCA2-associated and familial cases: long-term follow-up of the Dutch MRISC Screening Study. J Clin Oncol 28(36): 5265-5273.

Riley GF, Lubitz JD (2010) Long-term trends in Medicare payments in the last year of life. Health Serv Res 45(2): 565-576.

Saadatmand S, Tilanus-Linthorst MM, Rutgers EJ, Hoogerbrugge N, Oosterwijk JC, Tollenaar RA, Hooning M, Loo CE, Obdeijn IM, Heijnsdijk EA, de Koning HJ (2013) Cost-effectiveness of screening women with familial risk for breast cancer with magnetic resonance imaging. J Natl Cancer Inst 105(17): 1314-1321.

Saslow D, Boetes C, Burke W, Harms S, Leach MO, Lehman CD, Morris E, Pisano E, Schnall M, Sener S, Smith RA, Warner E, Yaffe M, Andrews KS, Russell CA (2007) American Cancer Society guidelines for breast screening with MRI as an adjunct to mammography. CA Cancer J Clin 57(2): 75-89.

Shen Y, Dong W, Esteva FJ, Kau SW, Theriault RL, Bevers TB (2007) Are there racial differences in breast cancer treatments and clinical outcomes for women treated at M.D. Anderson Cancer Center? Breast Cancer Res Treat 102(3): 347-356.

Shen Y, Parmigiani G (2005) A model-based comparison of breast cancer screening strategies: mammograms and clinical breast examinations. Cancer Epidemiol Biomarkers Prev 14(2): 529-532.

Shen Y, Parmigiani G (2006) Optimization of breast cancer screening modalities. In Probability, Statistics, and Modelling in Public Health, Nikoulina M, Commenges D, Huber C (eds), pp 405-420. Springer Business Media, Inc.: USA.

Shen Y, Wu D, Zelen M (2001) Testing the independence of two diagnostic tests. Biometrics 57(4): 1009-1017.

Shih YC, Elting LS, Pavluck AL, Stewart A, Halpern MT (2010) Immunotherapy in the initial treatment of newly diagnosed cancer patients: utilization trend and cost projections for non-Hodgkin's lymphoma, metastatic breast cancer, and metastatic colorectal cancer. Cancer Invest 28(1): 46-53.

Singletary SE, Allred C, Ashley P, Bassett LW, Berry D, Bland KI, Borgen PI, Clark G, Edge SB, Hayes DF, Hughes LL, Hutter RV, Morrow M, Page DL, Recht A, Theriault RL, Thor A, Weaver DL, Wieand HS, Greene FL (2002) Revision of the American Joint Committee on Cancer staging system for breast cancer. J Clin Oncol 20(17): 3628-3636.

Smith RA, Saslow D, Sawyer KA, Burke W, Costanza ME, Evans 3rd WP, Foster Jr RS, Hendrick E, Eyre HJ, Sener S (2003) American Cancer Society guidelines for breast cancer screening: update 2003. CA Cancer J Clin 53(3): 141-169.

Taneja C, Edelsberg J, Weycker D, Guo A, Oster G, Weinreb J (2009) Cost effectiveness of breast cancer screening with contrast-enhanced MRI in high-risk women. J Am Coll Radiol 6(3): 171-179.

Tengs TO, Wallace A (2000) One thousand health-related quality-of-life estimates. Med Care 38(6): 583-637.

Tilanus-Linthorst MM, Obdeijn IM, Hop WC, Causer PA, Leach MO, Warner E, Pointon L, Hill K, Klijn JG, Warren RM, Gilbert FJ (2007) BRCA1 mutation and young age predict fast breast cancer growth in the Dutch, United Kingdom, and Canadian magnetic resonance imaging screening trials. Clin Cancer Res 13(24): 7357-7362.

Ubel PA, Hirth RA, Chernew ME, Fendrick AM (2003) What is the price of life and why doesn't it increase at the rate of inflation? Arch Intern Med 163(14): 1637-1641.

UK CR (2012) Who is screened for breast cancer? Vol. 2014.

Warner E, Plewes DB, Hill KA, Causer PA, Zubovits JT, Jong RA, Cutrara MR, DeBoer G, Yaffe MJ, Messner SJ, Meschino WS, Piron CA, Narod SA (2004) Surveillance of BRCA1 and BRCA2 mutation carriers with magnetic resonance imaging, ultrasound, 
mammography, and clinical breast examination. JAMA 292(11): 1317-1325.

Weedon-Fekjar H, Lindqvist BH, Vatten LJ, Aalen OO, Tretl S (2008) Breast cancer tumor growth estimated through mammography screening data. Breast Cancer Res 10(3): R41.

Wood WC, Budman DR, Korzun AH, Cooper MR, Younger J, Hart RD, Moore A, Ellerton JA, Norton L, Ferree CR (1994) Dose and dose intensity of adjuvant chemotherapy for stage II, node-positive breast carcinoma. N Engl J Med 330(18): 1253-1259.

Wood WC, Weiss RB, Tormey DC, Holland JF, Henry PH, Leone LA, Rafla S, Silver RT, Carey RW, Lesnick GJ (1985) A randomized trial of CMF versus CMFVP as adjuvant chemotherapy in women with node-positive stage II breast cancer: a CALGB Study. World J Surg 9(5): 714-718.

Yabroff KR, Lamont EB, Mariotto A, Warren JL, Topor M, Meekins A, Brown ML (2008) Cost of care for elderly cancer patients in the United States. J Natl Cancer Inst 100(9): 630-641.

This work is published under the standard license to publish agreement. After 12 months the work will become freely available and the license terms will switch to a Creative Commons AttributionNonCommercial-Share Alike 3.0 Unported License. 